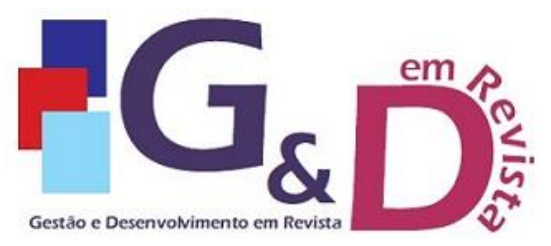

Gestão e Desenvolvimento em Revista

V. 7, N. 1, jan-jun/2021, p. 37-58.

ISSN online: $2446-8738$

Artigo recebido em: 21/06/2021

Artigo aprovado em: 31/08/2021

\title{
CARACTERÍSTICAS EMPREENDEDORAS EM PEQUENOS PRODUTORES RURAIS
}

\author{
Franciel Oliarski \\ Graduada em Administração pela Universidade Estadual do Centro-Oeste - UNICENTRO. \\ E-mail: franciel99@outlook.com
}

Antônio João Hocayen da Silva

Doutor em Administração pela Universidade Positivo - UP. Atualmente é Professor Adjunto Nível A do Curso de Administração na Universidade Estadual do Centro-Oeste - UNICENTRO.

E-mail: hocayen@yahoo.com.br

\section{Resumo}

O presente estudo teve como objetivo analisar as características empreendedoras de produtores rurais no interior do Paraná. Trata-se de uma pesquisa descritiva, que utilizou de uma abordagem qualitativa e do método dedutivo para análise dos dados coletados por meio de entrevistas estruturadas junto aos produtores rurais. Os resultados da pesquisa mostraram um perfil empreendedor entre os produtores da região, pois, além de características empreendedoras como, visão de oportunidade, inovação e habilidades administrativas, os produtores tomam atitudes como diversificação produtiva e busca por informações sobre o mercado, como forma de melhorar o desempenho da propriedade. Destaca-se ainda a instituição de parcerias e a formação de coletivos que permitem o compartilhamento de riscos e a comercialização em conjunto, garantindo a proteção dos empreendedores rurais das situações adversas, bem como, fortalecendo o poder de negociação dos mesmos em relação aos demais atores do mercado. Assim, concluiu-se que os produtores rurais possuem tanto características e atitudes empreendedoras, além de agirem de forma organizada dentro de suas propriedades, sendo ao mesmo tempo empreendedores e administradores de seus negócios. Cabe salientar que para o estudo do empreendedorismo rural pesquisadores devem estar atentos às características do meio em que investigação está sendo conduzida.

Palavras-Chave: Empreendedorismo. Produtores Rurais. Atividades Agropecuárias. Empreendedorismo Rural.

\begin{abstract}
This study aimed to analyze the entrepreneurial characteristics of rural producers in the interior of Paraná. This is a descriptive research, which used a qualitative approach and the deductive method to analyze the data collected through structured interviews with rural producers. The survey results showed an entrepreneurial profile among producers in the region, because, in addition to entrepreneurial characteristics such as vision of opportunity, innovation and administrative skills, producers adopt attitudes such as productive diversification and search for market information as a way to improve the performance of the property. Also noteworthy is the institution of partnerships and the formation of collectives that allow the sharing of risks and marketing together, ensuring the protection of rural entrepreneurs from adverse situations, as well as strengthening their negotiating power in relation to other actors from the market. Thus, it was concluded that rural producers have both entrepreneurial characteristics and attitudes, in addition to acting in an organized manner within their properties, being at the same time entrepreneurs and administrators of their businesses. It should be noted that, for the study of rural entrepreneurship, researchers must be aware of the characteristics of the environment in which the investigation is being conducted.
\end{abstract}

Keywords: Entrepreneurship. Farmers. Agricultural Activities. Rural Entrepreneurship. 


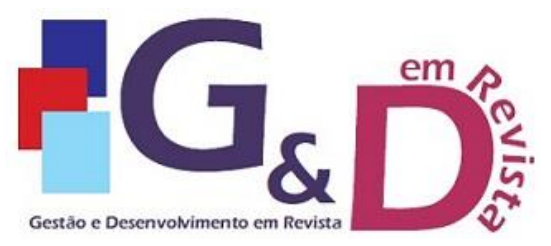

Gestão e Desenvolvimento em Revista

V. 7, N. 1, jan-jun/2021, p. 37-58.

ISSN online: $2446-8738$

Artigo recebido em: 21/06/2021

Artigo aprovado em: 31/08/2021

\section{INTRODUÇÃ̃O}

Muitas são as pesquisas científicas que buscam explicar o movimento do empreendedorismo ao redor do mundo. Em sua maioria são abordagens normativas e homogêneas que pouco refletem acerca das particularidades que distinguem muitos contextos empreendedores que se manifestam no meio rural (MUÑOZ; KIMMITT, 2019). As constantes mudanças no campo, evolução tecnológica e dos métodos de produção exigem do produtor rural capacidades administrativas, algo importante nos dias atuais, para manutenção da sobrevivência e da continuação da propriedade ou empresa agrícola. O agricultor deve ter esse comportamento, objetivando a maior lucratividade da sua propriedade (ARNOLD, 2011).

O homem do campo vem sendo visto como empresário ou empreendedor agrícola, já que suas propriedades se tornaram empreendimentos lucrativos, uma vez que se tornaram unidades organizacionais eficientes (BERNARDO; RAMOS; VILLS, 2019). Empreendedores rurais passaram a ser percebidos como agentes sociais vitais para o desenvolvimento econômico (DAS; PATNAIK; PATRA, 2019), tanto em contextos locais, como em setores macro-sociais. Depois da ascensão do termo empreendedorismo rural, a partir de 1990, as publicações acerca do tema aumentaram consideravelmente (BERNARDO; RAMOS; VILLS, 2019).

Para Bernardo, Ramos e Vills (2019), o termo empreendedorismo rural apesar de ser um processo que existe há décadas, faz pouco tempo que o termo passou a ser utilizado. $\mathrm{O}$ empreendedor rural se torna tão importante para o setor agrícola, como o empreendedor tradicional para as áreas do comércio, indústria e serviços. Provoca mudanças; $e_{\bar{j}}$ colabora no desenvolvimento de suas localidades rurais (FERREIRA; LASSO; MAINARDES, 2017), caracterizadas pela agricultura familiar. A agricultura familiar tem grande importância neste cenário por ser uma das principais fontes produtivas de alimentos, renda e emprego para a sociedade. Os agricultores familiares são chamados de empreendedores rurais em virtude de serem responsáveis pelos seus negócios (WEBER; MORGAN; WINCK, 2016).

Diante desta possibilidade, fez-se necessário caracterizar o homem do campo como portador de aptidões empreendedoras necessárias para a gestão dos negócios rurais. Que afloram por meio do empreendedorismo e, consequentemente, se desenvolvem a partir de métodos criativos de trabalho, desmistificando a ideia de que a agricultura familiar tem que ser realizada apenas para a subsistência e não como meio de alcançar maiores lucros e crescimento para o produtor rural (LIMA, 2010). Portanto, o indivíduo apresenta na sua personalidade traços e habilidades de um empreendedor (BRACHT; WERLANG, 2015; CAMPOS; LIMA, 2019). O chamado empreendedorismo rural vem ganhando importância, e mostra que a junção entre agricultura e empreendedorismo é possível, e ações empreendedoras podem ser realizadas no meio rural, propiciando $O$ crescimento produtivo das propriedades agrícolas e o desenvolvimento local (ROCHA; CABRAL, 2016).

Partindo do pressuposto de que o processo empreendedor tem como protagonista $\mathrm{o}$ indivíduo, e que o mesmo pode ser desenvolvido em qualquer contexto, a pesquisa teve como objetivo central analisar as características empreendedoras de produtores rurais em um município Paranaense. Nesse contexto, o empreendedor rural é aquele que apresenta capacidades distintas dos demais produtores rurais, ou seja, é diferenciado em termos de habilidades e competências apresentadas no cotidiano de organização e produção na propriedade (BRACHT; WERLANG, 2015). Apresenta habilidades que favorecem a impulsão ao 
surgimento de negócios inovadores, e, assim, o comportamento empreendedor se manifesta no campo, caracterizando o empreendedorismo rural. Assim, o estudo buscou responder ao seguinte questionamento: Quais características empreendedoras são observadas na prática de produtores rurais?

O indivíduo toma atitudes empreendedoras, ou seja, ações necessárias para que o empreendedorismo aconteça, $e_{\bar{j}}$ assim, surjam novos empreendimentos, favorecendo a economia da região onde estão inseridos, com novas oportunidades de trabalho e renda à população (SHAKIR, 2019). Para Krüger e Minello (2017), atitudes empreendedoras vêm crescendo e se espalhando amplamente em todo o mundo. Contexto em que, as universidades, por exemplo, têm papel fundamental na formação empreendedora de seus alunos para o mercado de trabalho.

Portanto, o presente estudo teve como objetivo analisar as características empreendedoras de produtores rurais no interior do Paraná. Para tanto, o estudo tem seu conteúdo estruturado em seis eixos. Após a breve apresentação do tema e a definição dos propósitos centrais, descritos na Introdução, seguem as Reflexões Teóricas, delimitadas a partir de diferentes abordagens conceituais, que direcionam para uma compreensão acerca das características empreendedoras e o empreendedorismo rural. Na sequência, os Procedimentos Metodológicos com a delimitação da classificação da pesquisa, atores sociais participantes, técnicas de coleta de dados e estratégias de análise. Os Resultados, que trazem uma compreensão acerca do fenômeno investigado, estão organizados em dois subtópicos buscando melhor responder ao problema de pesquisa assumido. Finalmente, as Considerações Finais, com uma discussão em torno das principais constatações da pesquisa e as propostas para futuros estudos, bem como, as Referencias Bibliográficas utilizadas.

\section{CARACTERÍSTICAS EMPREENDEDORAS E EMPREENDEDORISMO RURAL}

O termo empreendedorismo tem origem em 1437, na palavra francesa entrepreuner, que significa "intermediário", ou seja, "que está entre ou no meio do processo empreendedor". No século XVII o termo assumiu a noção de risco. No século XVIII e XIX o empreendedor assume um caráter mais próximo de empresário, que o tornava diferente do capitalista da época (HISRICH; PETERS; SHEPHERD, 2009). No Brasil, o empreendedorismo começou a ter apoio institucional a partir de 1990, quando criados Sebrae (Serviço Brasileiro de Apoio às Micro e Pequenas Empresas) e Softex (Sociedade Brasileira para Exportação de Software). Antes não se falava na criação de novos empreendimentos, a política e economia do país não eram favoráveis à elaboração de novos negócios. Além da falta de informação sobre o assunto (DORNELAS, 2005).

O empreendedorismo rural, como discutido por Moraes (2011), surgiu a partir de 1930, quando as famílias alemãs e italianas chegaram ao Brasil e passaram a residir em São Paulo, sobrevivendo da renda retirada da produção de café. Esses imigrantes trouxeram de seus países ferramentas e sementes, sendo estas utilizadas no país, possibilitando o surgimento de novas profissões. Essas novas atividades se formaram com o objetivo de sustento e consumo familiar. Logo, transformaram-se em empreendimentos de comercialização (LIMA, 2010). Desta forma, pode-se afirmar que o empreendedorismo rural, surgiu como uma opção ao maior aproveitamento das propriedades, que objetivando a maior rentabilidade gerou novas formas de trabalho, bem como a qualificação e diversificação de produtos, 
objetivando atender as exigências de mercado e pela sobrevivência dos produtores rurais da época (LIMA, 2015).

Tomei e Lima (2015) destacam que o produtor rural e o empreendedorismo parecem coisas totalmente incompatíveis, mas sua junção é possível e não precisa ser algo extremamente elaborado. O simples processo de tirar o leite da vaca e transformá-lo em queijo, que para o meio urbano é uma atividade industrial comum, é para o meio rural uma inovação. Assim, mediante características específicas os empreendedores criam novos negócios ou adaptam negócios existentes, sendo favorável economicamente à região onde o empreendedorismo acontece. Suas principais características são: ser inovador, ser o criador e dono do próprio negócio, ter a visão direcionada aos lucros, ou criar valor a partir de seu trabalho (FELIPE; SANTOS, 2017).

Bressant e Tidd (2009) destacam que características pessoais como: i) religião e família; ii) educação formal e experiência profissional prévia; e iii) o perfil psicológico, fazem do indivíduo um empreendedor. Aspectos que colaboram na manifestação de competências enriquecedoras e na compilação de ações, chamado por Sertek (2012) de potencial empreendedor, momento em que o indivíduo aproveita oportunidades com objetivo de satisfazer as necessidades e desejos dos clientes. A maioria dos empreendedores que triunfaram em seus negócios tem a percepção apurada de situações inusitadas, percebendo oportunidades muitas vezes disfarçadas e que aparecem do inesperado, por meio de mudanças, necessidades de novos processos e conhecimentos (SERTEK, 2012).

O empreendedor com visão de futuro e com o sonho de vencer, realiza investimentos em novos ou negócios já existentes, que na sua percepção tem grande potencial, correndo riscos de forma organizada e calculada, estando preparado para as adversidades do mundo dos negócios. Os investimentos em empreendimentos lucrativos beneficiam a sociedade com a geração de novos empregos e renda para a população. Assim sendo, é importante a existência destes, que com coragem buscam satisfazer seus anseios como empreendedor, provocando mudanças econômicas e sociais positivas (GARTNER, 1988; CRUZ, 2005; PETERS; HISRICH, 2002; PORCARO, 2006; ECKARDT; SHANE, 2003; BRESSANT; TIDD, 2009; SERTEK, 2012; DORNELAS, 2005; DORNELLAS; MAIA, 2018).

Essas características fazem dos empreendedores seres adaptáveis a situações difíceis, que arriscam em contextos onde pessoas comuns não arriscariam, um exemplo seria as decisões tomadas em cenários de altas pressões e riscos elevados, o que exige grande controle emocional. (HISRICH; PETERS; SHEPHERD, 2009). Feger, Vieira e Chemin (2016) afirmam que o empreendedor é dinâmico e líder de ações empreendedoras, destacando como principais aspectos a inovação e criação dentro de seu campo de atuação. O empreendedor organizado e que faz o planejamento das suas ações apresenta maior propensão ao sucesso, geralmente aqueles que se enquadram na vertente empreendedora por oportunidade e tem mais tempo para dedicação a seus negócios.

Sendo assim, empreendedores são homens e mulheres, que motivados por um sonho e em conjunto com características específicas não tem medo em arriscar. Pessoas que acreditam que investimentos são possíveis e que futuramente a probabilidade de lucro é alta. Pessoas que são constantemente impulsionadas por oportunidades de investimento em produtos e serviços, com o objetivo de buscar a independência financeira, se desvinculando de empresas onde são apenas empregados, ou de atividades que não são lucrativas (HISRICH; PETERS; 
SHEPHERD, 2009; FEGER; VIEIRA; CHEMIN, 2016).

A caracterização do empreendedor se divide em três conjuntos, cada um deles com características específicas, desde o início ao final do processo de empreendedorismo, e são os seguintes, de acordo com o Quadro 1.

QUADRO 1 - Conjunto de características do empreendedor.

\begin{tabular}{|c|l|}
\hline Conjunto & \multicolumn{1}{|c|}{ Características } \\
\hline De realização & $\begin{array}{l}\text { Procura por oportunidades, pro-atividade e iniciativa, } \\
\text { cálculo dos riscos, persistência, comprometimento com o } \\
\text { negócio, exigência da qualidade e eficiência da produção. }\end{array}$ \\
\hline De planejamento & $\begin{array}{l}\text { Organização por meio da busca de informações, } \\
\text { estabelecimento de metas, planejamento e monitoria } \\
\text { sistemática e constante. }\end{array}$ \\
\hline De poder & $\begin{array}{l}\text { Estabelecimento de redes de contatos, persuasão, } \\
\text { independência e autoconfiança. }\end{array}$ \\
\hline
\end{tabular}

Fonte: SEBRAE. Programa Empretec. 2014. Disponível em: <www.sebrae.com.br>. Acesso em: 23 Set., 2018.

Analogamente, o empreendedor apresenta características e trabalha com os recursos disponíveis, superando obstáculos muitas vezes colocados pelo ambiente onde está inserido, exerce suas atividades em situações imprevisíveis, principalmente se levado em conta fatores climáticos, que influenciam na produção das propriedades, elevando ou diminuindo a capacidade produtiva e, consequentemente lucrativa. Como um empreendimento da área urbana, a propriedade rural é um negócio que gera receita, custos e despesas, assim o produtor rural como empreendedor busca investir corretamente, reduzir os gastos e assim obter maiores lucros.

Produtores rurais são indivíduos que tem controle sobre a produção e que agregam valor ao produto final, inovando métodos produtivos através da combinação de recursos disponíveis (LIMA, 2010). Segundo o Senar (2014), o empreendedor rural é caracterizado conforme Quadro 2.

QUADRO 2 - Caracterização do empreendedor rural.

\begin{tabular}{|c|c|}
\hline Características & Descrição \\
\hline Vê as oportunidades & $\begin{array}{l}\text { Com visão apurada diferente das demais pessoas } \\
\text { enxerga as chances de negócios no cenário rural. }\end{array}$ \\
\hline $\begin{array}{l}\text { Tem habilidades para começar e } \\
\text { recomeçar se necessário }\end{array}$ & $\begin{array}{l}\text { O ambiente onde se insere não é obstáculo tão } \\
\text { grande, sabe trabalhar com fatores favoráveis e } \\
\text { desfavoráveis. }\end{array}$ \\
\hline $\begin{array}{r}\text { Capacidade de vender se } \\
\text { maneira difereno }\end{array}$ & $\begin{array}{l}\text { Sabe negociar seus produtos ou serviços de modo a } \\
\text { alcançar melhores resultados. }\end{array}$ \\
\hline Consegue ver a necessidade do mercado & $\begin{array}{l}\text { Quais os produtos, qualidade, preço, formas de } \\
\text { pagamento, entre outros fatores exigidos pelo } \\
\text { mercado. }\end{array}$ \\
\hline Tem uma boa rede de relacionamentos & $\begin{array}{l}\text { Sabe se relacionar com os funcionários, fornecedores } \\
\text { e clientes, ou seja, todos os envolvidos no processo } \\
\text { empreendedor. }\end{array}$ \\
\hline Tem a própria opinião & $\begin{array}{l}\text { Opinião que não muda independentemente da } \\
\text { situação e do cenário onde pretende inserir seu } \\
\text { empreendimento. }\end{array}$ \\
\hline Persistente & Não desiste diante de adversidades e desafios. \\
\hline Assume riscos & Toma para si a responsabilidade do possível fracasso. \\
\hline Um líder entusiasmado & $\begin{array}{l}\text { Animação devido a possibilidade do surgimento de um } \\
\text { novo, ou implementação em um negócio existente. }\end{array}$ \\
\hline Quer crescer sempr & 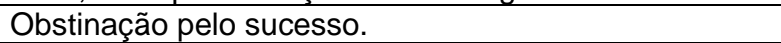 \\
\hline
\end{tabular}

Fonte: SENAR. Programa empreendedor rural. 2014. Disponível em: <http://senarms.org.br>. Acesso em: 30 Out., 2018. 
Para Cella (2002), o viés empreendedor é a base para que o produtor rural tenha sucesso nas suas atividades, e as características empreendedoras mais relevantes podem ser observadas no Quadro 3.

QUADRO 3 - Características do produtor rural com viés empreendedor.

\begin{tabular}{|c|l|}
\hline Características & \multicolumn{1}{|c|}{ Descrição } \\
\hline Competência & $\begin{array}{l}\text { Conhecimentos técnicos e produtivos, aptidões, } \\
\text { habilidades e atos que dão apoio para tomada de } \\
\text { decisão. }\end{array}$ \\
\hline Persistência & $\begin{array}{l}\text { Através da busca de informações para manter-se } \\
\text { competitivo no mercado. }\end{array}$ \\
\hline Compartilhamento de riscos & $\begin{array}{l}\text { Através de parcerias com associações e cooperativas } \\
\text { da região. }\end{array}$ \\
\hline Disponibilidade para aderir a novas \\
tecnologias & $\begin{array}{l}\text { Faz rotatividade do terreno com a produção de } \\
\text { diversos produtos. }\end{array}$ \\
\hline Habilidades administrativas & $\begin{array}{l}\text { Sabe que aderindo a novas tecnologias a execução do } \\
\text { processo produtivo pode ser facilitada e melhorada. }\end{array}$ \\
\hline Preservação do meio ambiente & $\begin{array}{l}\text { Através de organização, incluindo controle financeiro } \\
\text { dos custos e despesas necessários a produção. }\end{array}$ \\
\hline Envolvimento da família & $\begin{array}{l}\text { Produção realizada em espaços adequados. } \\
\text { produtivo quanto no planejamento e gerenciamento } \\
\text { dos negócios fora da propriedade. }\end{array}$ \\
\hline Gerenciamento de pessoal & $\begin{array}{l}\text { Divulgação de informações a todos os envolvidos } \\
\text { sobre as atividades do dia à dia e o futuro da } \\
\text { propriedade. }\end{array}$ \\
\hline Aproveitamento de oportunidades & $\begin{array}{l}\text { Reavaliação do processo produtivo e possíveis formas } \\
\text { de melhorá-lo. }\end{array}$ \\
\hline Experiência comercial & $\begin{array}{l}\text { Através de experiência comercial, define estratégias } \\
\text { de compra e venda do produto final. }\end{array}$ \\
\hline
\end{tabular}

Fonte: CELLA, D. Caracterização dos fatores relacionados ao sucesso do empreendedor rural. 2002. Disponível em: <www.teses.usp.br>. Acesso em: 11 Set., 2018.

Segundo Cella (2002), o produtor rural pode ser caracterizado como administrador, porque possui competências gerenciais capacitando-o a definir estratégias, analisar problemas e se relacionar com as pessoas. Arnold (2011) salienta que o setor rural está sendo à base de sustentação da economia do Brasil e os empreendimentos rurais são importantes. Assim sendo, é interessante que o produtor rural apresente características empreendedoras gerenciais, como habilidades de gestão para que os resultados da agricultura sejam satisfatórios economicamente. Habilidades que fazem do agricultor um empresário do campo.

\section{ENFOQUE METODOLÓGICO}

A presente pesquisa surgiu como descritiva, visto que foi realizada a descrição das características empreendedoras dos produtores rurais do município. Pesquisas descritivas são estruturadas especificamente para descrever características dos fenômenos sociais investigados (CASARIN; CASARIN, 2012). O processo descritivo é fundamental. Por meio dele se obtém resultados específicos que demonstram a relevância da pesquisa e a necessidade de novos levantamentos (MARCONI; LAKATOS, 2011).

O estudo classificou-se como qualitativo, que se caracteriza como a busca da compreensão detalhada dos significados e características situacionais apresentados pelos entrevistados, sem a utilização de métodos de quantificação dos dados (RICHARDSON et al., 2010). A estratégia de pesquisa foi o estudo de campo. Para Gil (2014) os estudos de campo procuram se aprofundar no entendimento de 
grupos ou comunidades de pessoas, por exemplo, o funcionamento da estrutura social dos mesmos e a interação entre suas partes.

Por se tratar de estudo qualitativo, o instrumento para coleta de dados foi à entrevista estruturada. Optou-se por esse modelo de entrevista juntamente aos produtores rurais em um município no interior do Paraná, visando estabelecer uma dinâmica de conversa mais flexível. As entrevistas são úteis na coleta de dados de pouca complexidade (HAIR JR et al., 2005). Segundo Richardson et al. (2010), a entrevista é uma técnica importante, porque proporciona a interação direta entre as pessoas, estreitando as relações. Embora Gil (2014) reforce que em estudo de campo seja priorizada, além das entrevistas, a observação direta da realidade investigada, como coleta de dados, no presente estudo a técnica de observação não foi adotada em virtude da dificuldade de permanência nas propriedades rurais para acompanhamento do cotidiano dos produtores.

O número de entrevistados foi definido ao final do processo de entrevista pelo critério de saturação dos dados. Os produtores rurais entrevistados inicialmente foram escolhidos por acessibilidade, e, na sequência, pelo critério de bola de neve, em que o primeiro entrevistado indicava o segundo e assim sucessivamente. Já os entrevistados, por conveniência, foram produtores rurais da própria família e residentes nas demais localidades. Para Gil (2014), pelo critério de acessibilidade o pesquisador faz a seleção dos elementos que tem acesso, e que possam representar a realidade investigada.

As entrevistas foram realizadas em 2019, de forma presencial, com o uso de um gravador. Ao todo foram realizadas 11 entrevistas com produtores rurais que desenvolvem atividades agropecuárias em propriedades de pequeno porte, caracterizadas por uma prática de cotidiana de organização e produção familiar. Para Baldin e Munhoz (2011), bola de neve, ou no inglês, snowball, é a técnica de amostragem que utiliza de cadeia de referência, ou seja, um tipo de rede. Pelo critério de saturação os dados chegaram a um limite, e, assim, foram saturados teoricamente. Momento em que se interrompeu a coleta, quando se percebeu que os elementos para a teorização almejada não eram mais vistos no campo de estudos. A repetição de informações determinava o limite (FONTANELLA et al., 2011).

Depois de organizados, os dados foram analisados considerando alguns parâmetros metodológicos importantes. Por meio de análise os dados foram organizados e abreviados, possibilitando o encontro de respostas ao problema proposto. Depois a interpretação veio dar o sentido mais amplo às respostas, por meio da ligação com os apontamentos teóricos já existentes na área de pesquisa (GIL, 2014). A interpretação focou nos dados que realmente interessavam a pesquisa, as características do empreendedor rural, sem a preocupação com dados que não condiziam com a mesma. Assim, utilizou-se a técnica de análise de conteúdo. Para Vergara (2011), essa técnica consiste no tratamento dos dados visando interpretar o que é dito sobre determinado assunto. Segundo Hair Jr. et al. (2005), nesse tipo de análise os dados são obtidos por meio de observação ou por mensagem de texto escrito. E com análise sistemática o pesquisador examina os temas principais e identifica o conteúdo.

No Quadro 4 foram descritas as duas categorias analisadas durante a pesquisa, seus respectivos conceitos, tendo como base as concepções teóricas apresentadas pelos autores que sustentam teoricamente o estudo, e os principais elementos de análise que as formam, concebidos como dimensões operacionais de 


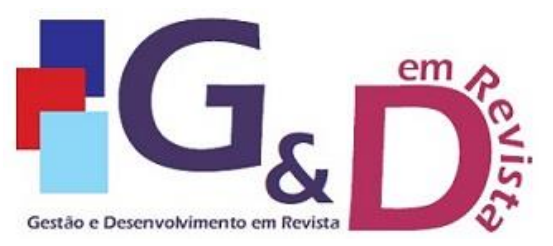

Gestão e Desenvolvimento em Revista V. 7, N. 1, jan-jun/2021, p. 37-58.

ISSN online: $2446-8738$

Artigo recebido em: 21/06/2021

Artigo aprovado em: 31/08/2021

compreensão do fenômeno social investigado em alinhamento aos construtos teóricos que compõem as categorias da pesquisa. Portanto, dimensões, conceitos e elementos de análise formam a grade fechada que permitiu compreender quem é o produtor rural empreendedor, bem como, as atitudes que caracterizam sua forma de agir no cotidiano.

QUADRO 4 - Categorias, dimensões e elementos de análise.

\begin{tabular}{|c|c|c|}
\hline Categorias & Dimensões e Conceitos & Elementos de Análise \\
\hline Perfil Empreendedor & $\begin{array}{c}\text { O indivíduo com perfil } \\
\text { empreendedor tem capacidade de } \\
\text { realizar coisas novas, pôr em } \\
\text { prática ideias novas (ARNOLD, } \\
\text { 2011). } \\
\text { Por tomada de decisão o } \\
\text { empreendedor atua no ambiente } \\
\text { em que se encontra, está } \\
\text { conectado à geração e } \\
\text { desenvolvimento de oportunidades } \\
\text { (FELIPE; SANTOS, 2017). }\end{array}$ & $\begin{array}{c}\text { Meios utilizados na produção dos } \\
\text { produtos da propriedade; } \\
\text { Formas e técnicas produtivas; } \\
\text { Conhecimentos do produtor rural; } \\
\text { Informações que o produtor possui } \\
\text { sobre o mercado; } \\
\text { Uso de tecnologias no processo } \\
\text { produtivo; } \\
\text { Influência familiar nas atividades } \\
\text { agropecuárias; } \\
\text { Definição de estratégias de compra } \\
\text { de insumos e da venda do produto } \\
\text { final; } \\
\text { Visão de futuro do produtor rural; } \\
\text { Produtos produzidos na } \\
\text { propriedade; } \\
\text { Busca por inovações nas práticas } \\
\text { cotidianas da propriedade; e } \\
\text { Nível de obstinação do produtor } \\
\text { rural pelo sucesso do negócio. }\end{array}$ \\
\hline $\begin{array}{c}\text { Atitudes } \\
\text { Empreendedoras }\end{array}$ & $\begin{array}{c}\text { São características obtidas durante } \\
\text { a vida, que determinam } \\
\text { comportamentos diante de uma } \\
\text { situação, na condução de seus } \\
\text { negócios e na orientação no } \\
\text { trabalho (BACH; CERETTA; } \\
\text { ROCHA, 2018). } \\
\text { Atitude empreendedora é o agir } \\
\text { conforme características } \\
\text { comportamentais (SIQUEIRA et al., } \\
\text { 2014). }\end{array}$ & $\begin{array}{c}\text { Métodos de organização das } \\
\text { atividades; } \\
\text { Meios de enfrentamento das } \\
\text { barreiras; } \\
\text { Processo de tomada de decisões; } \\
\text { É inovador ou trabalha de maneira } \\
\text { tradicional na produção da } \\
\text { propriedade; } \\
\text { As ações do dia à dia de trabalho } \\
\text { são planejadas, com auxílio de } \\
\text { informações, e assim ocorre } \\
\text { estabelecimento de metas e } \\
\text { monitoramento constante e } \\
\text { sistemático do trabalho na } \\
\text { propriedade; } \\
\text { O indivíduo é persuasivo, forma } \\
\text { rede de contatos e é autoconfiante } \\
\text { ao realizar as atividades da } \\
\text { propriedade; } \\
\text { Ocorrência de rotatividade do } \\
\text { terreno, com a realização de } \\
\text { diferentes culturas; e } \\
\text { Apoio ou não de cooperativas ou } \\
\text { associações da região a produção } \\
\text { rural. }\end{array}$ \\
\hline
\end{tabular}

Fonte: O autor (2019).

Posteriormente, as entrevistas foram transcritas, $e_{\bar{j}}$ por meio de grade fechada, as categorias de análise foram definidas preliminarmente de acordo com o objetivo da pesquisa, sendo seus elementos obtidos no material selecionado, que foi lido novamente, definindo-se as unidades de análise, palavra, expressão, frase, parágrafo. No final o conteúdo obtido foi analisado por interpretação, confrontando os resultados alcançados com a teoria base do estudo. 


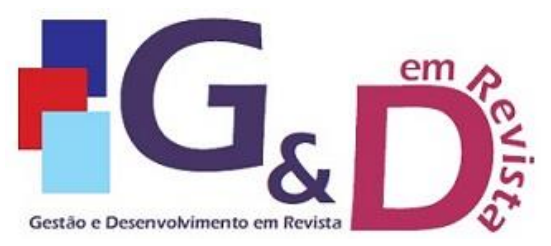

Gestão e Desenvolvimento em Revista

V. 7, N. 1, jan-jun/2021, p. 37-58.

ISSN online: $2446-8738$

Artigo recebido em: 21/06/2021

Artigo aprovado em: 31/08/2021

\section{APRESENTAÇÃO E DESCRIÇÃO DOS RESULTADOS}

\subsection{CARACTERIZAÇÃO DO PERFIL DOS EMPREENDEDORES RURAIS}

A partir dos dados coletados é possível constatar, considerando os relatos dos produtores rurais, que estes têm visão estratégica com foco em oportunidade. Por meio de planejamento e inovação buscam realizar suas atividades de modo que possam garantir sustentabilidade das atividades desenvolvidas na propriedade. Os produtores buscam manter-se competitivos a partir da análise das oportunidades que o mercado de atuação oferece, considerando as forças macro ambientais e micro ambientais que interagem cotidianamente com as práticas sociais dos produtores. Além do planejamento de suas ações, percebe-se o uso de ferramentas e equipamentos que possibilitam o melhor desempenho de suas propriedades de modo que se mantenham competitivas, com produtividade satisfatória e qualidade diferenciada. Parâmetros que correspondem às exigências do mercado. Aspectos que podem ser comprovados a partir dos relatos abaixo:

\footnotetext{
"[...] daí já com dezoito anos percebi uma chance melhor de ter maior renda com a produção de tabaco, numa propriedade de quatro alqueires [...]" (Entrevistado 1).

"Pelo ano de 2003/2004, meu pai colocou uma estufa de fumo, e fomos trabalhar com o fumo [...]" (Entrevistado 2).

"[...] compramos um trator, também os implementos pra trabalhar com milho, feijão e soja, compramos mais terreno, arrendamos dos vizinhos para as plantações, consegue ir melhorando, mais necessita de muito trabalho e esforço, e planejamento [...]" (Entrevistado 3).

"[...] coloquei um viveiro de mudas para consumo próprio e também para venda, a partir dali fui observando, não digo que fiz uma pesquisa de preço ou algo parecido sobre a erva mate, tentei então aumentar a produção e a qualidade das mudas para obter uma renda maior". [...] comecei a observar que soja, feijão e milho eram dessecados e limpos de melhor forma, e a erva mate sempre suja, o que a gente chama de quiçaça, resolvi então colocar herbicida, aumentou muito a produção, por exemplo, de 10 toneladas subiu para 30 toneladas, isso em 2 ou 3 anos [...]" (Entrevistado 8).
}

Diante dos resultados encontrados, foi possível perceber que as características demonstradas pelos empreendedores assemelham-se com as reflexões de Dornelas (2005), em que são ideias que surgem ao acaso. Os empreendedores têm visão de oportunidade, propiciando o surgimento de novos empreendimentos, alinhando-se aos resultados encontrados por Sohns e Diez (2018) que destacaram o empreendedorismo por oportunidades entre agricultores rurais no Vietnã.

Contudo, para que isso seja possível exige-se do empreendedor planejamento de suas ações, para o maior aproveitamento das oportunidades. Corrobora-se ainda com as reflexões de Hisrich, Peters e Shepherd (2009), tendo em vista que o indivíduo empreendedor, ao perceber as oportunidades a seu redor busca pelo investimento, porque tem a visão do surgimento de um novo negócio promissor. Processo potencializado pela implementação de inovação com a utilização de equipamentos e técnicas que propiciem desempenho superior.

Alinha-se ainda às reflexões de Lima (2010) ao reforçar a ideia de inovação. O produtor rural empreendedor inova seus métodos de produção com a junção dos recursos disponíveis em sua propriedade. Dessa forma, é possível obter melhores resultados e tornar realidade a visão de oportunidade percebida. Processo que auxilia não só no melhor desempenho, mas na facilitação do processo produtivo, saindo de modelos tradicionais de produção para modelos inovadores. Sendo assim, 


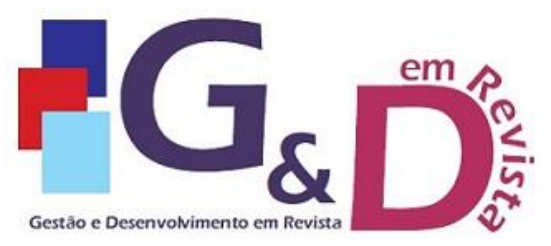

Gestão e Desenvolvimento em Revista

V. 7, N. 1, jan-jun/2021, p. 37-58.

ISSN online: $2446-8738$

Artigo recebido em: 21/06/2021

Artigo aprovado em: 31/08/2021

o processo inovador está diretamente ligado a dinamicidade apresentada pelo indivíduo empreendedor, ou seja, por ser dinâmico o mesmo procura por métodos inovadores de realização do trabalho (FEGER; VIEIRA; CHEMIN, 2016).

O empreendedor responsável pelo negócio representa um indivíduo dinâmico, influenciador das pessoas ao seu redor, criativo e inovador no dia a dia de suas atividades na propriedade. O inovar tem como objetivo melhorar ou criar novos métodos produtivos. A partir dos dados foi possível observar que os produtores se mostraram detentores de habilidades administrativas, característica empreendedora importante para o funcionamento eficiente de um empreendimento rural. Possivelmente, desenvolve essas habilidades como forma de obter resultados superiores por meio de suas atividades agropecuárias. Contudo, as ações organizam-se de acordo com as exigências de cada cultura, o que pode ser observado nos relatos abaixo:

"Tento perceber como anda o mercado, por exemplo, muitas pessoas plantam o feijão não quer dizer que também vou plantar, tem bastante oferta o preço vai diminuir, assim você investe em outras áreas, terá o produto que com uma pequena oferta o preço dele aumenta. Na minha opinião deve-se investir em áreas que estão ruins, porque assim você terá a lavoura pronta no momento em que o preço daquele produto sobe [...]" (Entrevistado 2).

"[...] vou na empresa e digo, tenho quantidade e qualidade e quero preço x [...] são necessários investimentos na produção e é preciso pensar bem se o produto final tem preço e se os investimentos vão ter o retorno esperado, por isso é difícil não poder dar o valor ao produto final [...]" (Entrevistado 8).

"Nesses últimos anos o custo de produção se tornou caro, sem saber se a propriedade terá lucro ou prejuízo, ou seja, o agricultor fica sem saber se planta ou não devido a esses custos, porque não há certeza de como estarão os preços dos produtos mais adiante" (Entrevista 11).

Constatações que se alinham aos postulados de Cella (2002), uma vez que o indivíduo possuidor de habilidades administrativas estará preparado para as exigências do mercado, satisfazendo as necessidades dos consumidores. Conforme discutido na teoria, a caracterização empreendedora se divide em três conjuntos. $O$ segundo conjunto é o de planejamento, processo em que o empreendedor se organiza por meio da busca de informações que possa auxiliá-lo na administração do empreendimento. Dessa forma a oportunidade percebida anteriormente pode tornar-se um novo negócio, favorecendo economicamente toda sociedade, com o surgimento de novos empregos e renda a população, devido à maior circulação de capital no mercado (SEBRAE, 2014).

As habilidades de gestores são essenciais na medida em que passam os empreendedores a serem exigidos pelo mercado. Inicialmente, percebe-se a forte influência do mercado consumidor que é muito exigente quanto à qualidade final dos produtos comercializados. Além de administrar sua relação com o mercado consumidor, o empreendedor rural precisa estar atento aos custos aplicados ao processo de compra de insumos, como máquinas e equipamentos, bem como, produtos para tratamento de pragas e adubação das lavouras. Conhecer os fatores e estar atento às variações de preços pode representar uma habilidade do empreendedor que garante viabilidade do negócio rural. Características percebidas nos relatos abaixo:

\footnotetext{
"Vejo o comércio como dificultador, deve-se ter um bom produto para ser entregue. [...] se o clima é desfavorável acaba-se por tomar alguns prejuízos devido a influenciar na qualidade dos produtos [...]" (Entrevistado 3 ).

"[...] os altos preços dos insumos agrícolas influenciados por altos impostos cobrados, e o produto nosso não tem valor, os preços na maioria das vezes são baixos" (Entrevistado 6).
} 


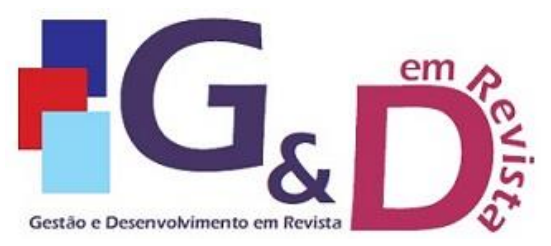

Gestão e Desenvolvimento em Revista

V. 7, N. 1, jan-jun/2021, p. 37-58.

ISSN online: $2446-8738$

Artigo recebido em: 21/06/2021

Artigo aprovado em: 31/08/2021

\begin{abstract}
"A falta de insumos aprovados pelo ministério da agricultura, de uma fórmula para adubação, falta de estudos sobre pragas e doenças que atingem a erva mate" (Entrevistado 8).

"Os custos dos insumos, adubo químico e adubo orgânico, além da falta de pesquisas
\end{abstract} relacionadas à produção de erva mate [...]" (Entrevistado 9).

Cella (2002) salienta que por meio de experiência comercial o empreendedor elabora meios de compra e venda do produto final. Procura comprar os insumos mais baratos para redução dos custos produtivos, não influenciando diretamente na qualidade do produto final, possibilitando agregar valor ao produto final, mesmo com a redução de custos de produção. Assim, o processo de tomada de decisão para o empreendedor rural representa uma característica essencial, uma vez que, está ligado à junção de inúmeras informações para a definição das culturas mais adequadas ao longo de um ciclo produtivo.

No empreendedorismo tradicional a decisão geralmente é tomada pelo próprio empreendedor. No caso do empreendedorismo rural esse procedimento acontece de forma diferente, o que se pode notar é que há um grande envolvimento da família na tomada de decisão, principalmente, relacionado à questão do que será produzido durante o período de safra. O que pode ser observado nos relatos abaixo:

\begin{abstract}
"Por meio de conversas juntamente com a família, uma decisão de um dia vai ser para o ano todo, por exemplo, se continua produzindo o tabaco ou produz outra coisa" (Entrevistado 1).

"Conforme as épocas de cada cultura, entre os familiares tomamos as decisões dos melhores dias para o plantio, dos cuidados necessários para as plantas, do melhor momento para a colheita e principalmente a hora certa de comercializar o produto" (Entrevistado 3).

"Compartilho com minha esposa, mas quem participa efetivamente na tomada de decisões é meu filho que cursa agronomia, decisões relacionadas ao manejo de solo, o que plantar e no momento de comercialização, as decisões são tomadas juntamente com a família, mas tem assistência técnica da cooperativa agrícola do município, o primeiro direcionamento vem do agrônomo responsável, sobre manejo de pragas e doenças, rotação de culturas, correção do solo, isso relacionado à atividade, mas as decisões do que e quando plantar são tomadas com os familiares" (Entrevistado 4).
\end{abstract}

Desse modo, destaca-se que o envolvimento da família ocorre desde o início ao final do período de safra, tanto na gestão do empreendimento, quanto na execução das atividades do processo produtivo. O que se pôde perceber é que os produtores buscam o envolvimento familiar, tanto na administração, quanto nos processos de produção, porque estão diretamente ligados a propriedade. Disponibilizam, principalmente, a mão de obra, algo essencial para que o processo ocorra, devido a diminuição dos custos produtivos.

Nesse sentido, percebe-se a aproximação dos resultados com os apontamentos de Cella (2002). O envolvimento da família pode impulsionar o sucesso do empreendimento rural porque os membros familiares atuam de forma mais abrangente. Desenvolvem atividades gerenciais e administrativas, bem como, atividades que necessitam de mão de obra braçal, evitando custos produtivos, possibilitando o sucesso empreendedor. A família representa então a base de sustentação para o bom desempenho do empreendimento rural.

Importante observar que, embora as decisões sejam tomadas no contexto familiar, parcerias e relacionamentos com outras organizações do setor são buscadas pelos empreendedores com o intuito de levantar informações estratégicas acerca do mercado, considerando-se, consumidores, fornecedores, concorrentes e gestores públicos. Nesse sentido, as decisões familiares são tomadas de forma 


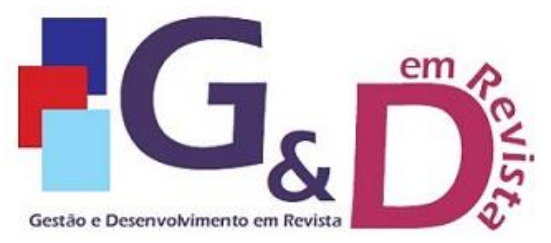

Gestão e Desenvolvimento em Revista

V. 7, N. 1, jan-jun/2021, p. 37-58.

ISSN online: $2446-8738$

Artigo recebido em: 21/06/2021

Artigo aprovado em: 31/08/2021

coletiva com base no conjunto de informações obtido de atores sociais externos ao contexto familiar, como destacado nos relatos abaixo:

\begin{abstract}
"Temos apoio por parte da cooperativa do município de Prudentópolis, com assistência de agrônomos. Por meio de conversa com os mesmos, mostramos em quais áreas serão realizadas as culturas, eles então definem qual a melhor cultura para aquele solo, as melhores sementes, qualidade das mesmas, e quais os melhores adubos a serem colocados e os melhores agrotóxicos para pulverização das plantas já nascidas, ou seja, procurar por informações com pessoas do mercado" (Entrevistado 6).
\end{abstract}

"[...] Além disso, converso com a família, e também com técnicos agrícolas e engenheiros agrônomos que acompanham as produções agrícolas" (Entrevistado 7).

Finalmente, com base nos dados é notável que os produtores rurais apresentam obstinação pelo sucesso do empreendimento, porque possuem visão diferenciada, principalmente das oportunidades que surgem. Percebem que seus empreendimentos rurais apresentam um grande potencial lucrativo, e sabem que o investimento na propriedade possivelmente terá retorno financeiro. Buscam fazer o planejamento no início de cada safra e de acordo com cada cultura produtiva, como a produção de tabaco, feijão, milho e soja. Planejamento que consiste no conhecimento das épocas para a produção das diferentes culturas, do ambiente de trabalho e do processo produtivo.

Notou-se que os produtores buscam tanto a utilização de formas tradicionais de produção, quanto meios inovadores, principalmente levando-se em conta a automatização das propriedades. Buscam ainda estabelecer objetivos e metas de quantidades produtivas possíveis, de acordo com as áreas de plantio. Considerando os custos produtivos, atuam na definição de estratégias de compra de insumos e de venda, com objetivo da redução de custos produtivos para que a propriedade se torne lucrativa. Dessa forma, é possível afirmar que os produtores rurais da região da pesquisa apresentam perfil empreendedor, inicialmente porque são donos do próprio negócio, e, porque administram suas propriedades como empreendimentos possíveis de rendimentos futuros. $O$ quadro 5 sintetiza as características empreendedoras percebidas mediante os dados analisados.

\begin{tabular}{l} 
QUADRO 5 - Caracterização empreendedora dos produtores rurais. \\
$\qquad$\begin{tabular}{|c|l|}
\hline Características & \multicolumn{1}{c|}{ Descrição } \\
\hline Planejamento das atividades & $\begin{array}{l}\text { O produtor faz o planejamento da safra, conforme as } \\
\text { exigências da cultura de produção desenvolvida } \\
\text { naquele período. }\end{array}$ \\
\hline Habilidades administrativas & $\begin{array}{l}\text { Gestão e organização dos processos dentro da } \\
\text { propriedade, por exemplo, redução de custos } \\
\text { produtivos, como forma de maior lucratividade, } \\
\text { habilidade essencial, principalmente para os pequenos } \\
\text { produtores. }\end{array}$ \\
\hline Experiência comercial & $\begin{array}{l}\text { O produtor conhece as necessidades do mercado, } \\
\text { qual a qualidade e quantidade do produto que o } \\
\text { mesmo procura. }\end{array}$ \\
\hline Visão de oportunidades & $\begin{array}{l}\text { Enxerga as oportunidades de lucratividade por meio } \\
\text { de seus negócios agropecuários. }\end{array}$ \\
\hline Involvimento da família & $\begin{array}{l}\text { Tanto nas atividades de gestão, quanto nos processos } \\
\text { produtivos dentro da propriedade, a mão de obra é } \\
\text { principalmente familiar. }\end{array}$ \\
\hline $\begin{array}{l}\text { Os produtores buscam por meios inovadores, } \\
\text { principalmente a utilização de máquinas que } \\
\text { promovam a diminuição de mão de obra dentro das } \\
\text { propriedades. }\end{array}$
\end{tabular} \\
\hline
\end{tabular}

Fonte: Os autores (2019). 
Portanto, é possível caracterizar os produtores rurais investigados como detentores de perfil empreendedor, cujas atitudes empreendedoras estão atreladas aos processos de planejamento e de organização das atividades agropecuárias.

\subsection{ATITUDES TOMADAS PELOS PRODUTORES RURAIS}

A análise dos dados permitiu compreender que atitudes dos empreendedores rurais são tomadas como meio de manter a produção agropecuária de forma satisfatória. São persistentes nas suas atividades, mesmo diante das dificuldades impostas pelo ambiente em que estão inseridos, como o clima, por exemplo, desfavorável a produção agropecuária, em casos de períodos de seca ou períodos chuvosos. Desse modo, é possível enfatizar que, de acordo com os dados observados, a capacidade de apropriar-se das condições locais e, assim, constituir uma dinâmica cotidiana de ações que, adaptadas ao contexto, possibilitem a condução das atividades e a realização dos objetivos traçados, corroboram com as constatações do estudo de Muñoz e Kimmitt (2019), ao apontarem para a importância do local biofísico do empreendedorismo rural, atrelado ao ambiente físico de um contexto, como determinante da atividade empreendedora.

Os dados apontam ainda que os produtores praticam uma produção para o consumo próprio e a produção para o mercado. Para tanto, é possível observar que existe a busca pelo equilíbrio da produção, garantindo assim a soberania alimentar da família, sem a dependência do mercado, bem como, a rentabilidade da propriedade por meio da oferta de produtos que atendem as necessidades dos consumidores. Aspectos comprovados pelos relatos a seguir:

\footnotetext{
"Também plantamos para o consumo o arroz crioulo, uma área de plantação de milho para alimentação do gado e de porcos, sendo sua carne, respectivamente, consumidas pela família, e, assim, tem alguns alimentos produzidos aqui mesmo sem ser necessário comprar no supermercado, algo mais natural. Para comercialização está em primeiro lugar o fumo, depois um pouco de feijão e soja, além da cebola [...]" (Entrevistado 3).

"[...] fiz o curso de técnico em agropecuária e comecei a trabalhar na atividade agrícola [...]" (Entrevistado 4).
}

As constatações alinham-se às concepções de Sebrae (2014), uma vez que, o empreendedor rural busca por informações para que possa produzir de forma mais correta, saber como devem ser realizados os processos produtivos, como é o produto, ou o serviço a ser realizado. Complementa-se às reflexões de Cella (2002), tendo em vista que, na diversificação produtiva ocorre então a rotatividade do terreno da propriedade. Consequentemente, a mesma se torna mais lucrativa, já que são produzidos diferentes produtos no mesmo espaço, mas em épocas diferentes.

Uma das saídas encontradas pelos empreendedores rurais diz respeito ao compartilhamento de riscos. Juntamente às cooperativas da região, como de crédito, buscam financiar a produção. As cooperativas de produção disponibilizam os insumos necessários a produção agropecuária. Um dos entrevistados, por exemplo, vê as cooperativas de produção como aliadas, principalmente, se forem considerados os pequenos produtores. O produto final é depositado juntamente com os de demais produtores, e, assim, se torna possível a comercialização a valores superiores, já que os lotes são comercializados em conjunto. Aspectos percebidos nos relatos abaixo:

"[...] quando acontecem alguns imprevistos, busco por alternativas como financiamento junto a bancos e cooperativas de crédito da região, como forma de continuar a produção agrícola da propriedade" (Entrevistado 3). 


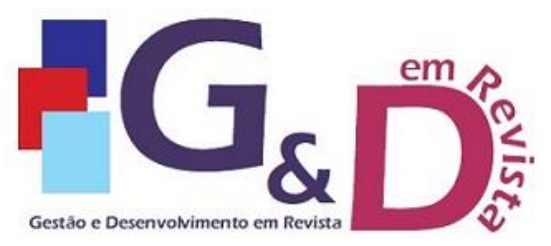

Gestão e Desenvolvimento em Revista

V. 7, N. 1, jan-jun/2021, p. 37-58.

ISSN online: $2446-8738$

Artigo recebido em: 21/06/2021

Artigo aprovado em: 31/08/2021

"[...] vejo a cooperativa como grande aliada dos pequenos produtores, dá condições iguais na compra de defensivos e venda do produto, o grande produtor coloca o produto junto com os pequenos produtores, se torna um volume maior e a cooperativa se torna uma grande ferramenta ao pequeno produtor, cada vez mais". (Entrevistado 4).

Atitudes em direção à construção de relacionamentos e parcerias se justificam em virtude de o mercado consumidor apresentar-se exigente. Consumidores estão atentos à qualidade dos produtos que saem das propriedades rurais. Como os processos produtivos evoluem rapidamente com a implementação de novas tecnologias é necessário que os empreendedores rurais estejam atentos quanto às mudanças que ocorrem. Os resultados corroboram com os apontamentos de Liu, Sim e Feng (2019), que analisando o contexto de empreendedores rurais na China, perceberam que o coletivo da comunidade tem papel central na constituição das atividades desempenhadas pelos empreendedores. Ou ainda com as discussões de Muñoz e Kimmitt (2019), ao afirmarem sobre a importância do contexto micro-social para os empreendedores rurais, perceberam que os vizinhos se apresentam como parceiros nas relações comerciais.

Outro fator constatado na prática dos empreendedores no meio rural é adoção de aparato tecnológico para o trabalho cotidiano nas propriedades. A tecnologia pode ser entendida como algo benéfico. Facilita o processo produtivo nas propriedades, diminui principalmente a mão de obra, pois são procedimentos cada vez mais automatizados. Percebendo isso, os empreendedores rurais destacam-se como indivíduos dispostos a adotar novas tecnologias, desde que suas propriedades suportem o investimento financeiro e possibilite o retorno esperado. Aspectos que podem ser constatados nos relatos adiante:

"[...] somente o tabaco que utiliza um pouco de equipamentos mais modernos [...]" (Entrevistado 1).

"Acompanhar as inovações tecnológicas porque as que utilizo são limitadas pelos equipamentos que tenho, vem uma nova tecnologia e é necessário um novo equipamento, e é necessário mais investimento e a propriedade não suporta [...]" (Entrevistado 4).

"Tudo mecanizado, com a utilização de trator e equipamentos próprios para o plantio e cuidados da lavoura [...]" (Entrevistado 6).

"Hoje temos mais tecnologia empregada nas atividades da propriedade, tentando sempre acompanhar o que há de mais novo no mercado, para assim aumentar a produção [...]" (Entrevistado 10).

O mercado consumidor é exigente, principalmente, em relação à qualidade dos produtos que saem das propriedades rurais, e como os processos produtivos evoluem rapidamente, com a implementação de novas tecnologias para que a produção satisfaça essas exigências, é necessário que os produtores rurais estejam atentos quanto às mudanças tecnológicas que surgem, visando garantir diferenciais em relação aos concorrentes. Sendo assim, as atitudes percebidas assemelham-se aos postulados apontados por Cella (2002), visto que os empreendedores rurais sabem que aderindo a novas tecnologias o processo produtivo se torna cada vez mais simplificado. O trabalho acaba sendo realizado por meio da utilização de implementos específicos e máquinas criadas como forma da redução da força braçal empregada nas atividades da propriedade.

Portanto, o que foi possível perceber é que são utilizadas pelos empreendedores rurais do estudo máquinas como: tratores, colheitadeiras, implementos para preparação do solo, plantio das sementes, pulverização tanto do solo quanto das plantas, caminhões para transporte da produção, entre outros, estes 
na produção dentro das propriedades maiores que tem como principais produtos os cereais.

Em síntese, são percebidas as seguintes atitudes empreendedoras entre os empreendedores rurais estudados (Quadro 6).

QUADRO 6 - Atitudes empreendedoras dos produtores rurais.

\begin{tabular}{|c|l|}
\hline Atitudes & \multicolumn{1}{|c|}{ Descrição } \\
\hline Diversificação produtiva & $\begin{array}{l}\text { O produtor realiza a variação de produção, por meio } \\
\text { da diversificação de culturas, conforme épocas } \\
\text { específicas. }\end{array}$ \\
\hline Busca por conhecimento & $\begin{array}{l}\text { Por meio da participação em cursos sobre atividades } \\
\text { agrícolas, além de conversas junto a técnicos e } \\
\text { profissionais responsáveis pela orientação junto as } \\
\text { propriedades. }\end{array}$ \\
\hline Disponibilidade para aderir a novas & $\begin{array}{l}\text { Sabem que aderindo a novas tecnologias, sendo estas } \\
\text { viáveis a propriedade, se mantém competitivos no } \\
\text { mercado, acompanhando seu desenvolvimento. }\end{array}$ \\
\hline tecnologias & $\begin{array}{l}\text { Junto a cooperativas de crédito e de produção da } \\
\text { região financiam sua safra. }\end{array}$ \\
\hline Compartilhamento de riscos & $\begin{array}{l}\text { Trabalham diretamente com fatores climáticos } \\
\text { favoráveis ou desfavoráveis, sendo necessária a } \\
\text { persistência, já que os resultados produtivos e e } \\
\text { lucrativos variam de safra para safra. }\end{array}$ \\
\hline
\end{tabular}

Fonte: Os autores (2019).

Os produtores rurais por meio de atitudes específicas procuram a manutenção da lucratividade de suas propriedades, buscam por alternativas em que possam manter ou melhorar o desempenho de suas atividades. A variação produtiva nas propriedades é uma das atitudes a se destacar, uma vez que, eleva a chance de resultados superiores. Práticas que podem ser atribuídas a um processo de fortalecimento das atividades empreendedoras rurais, corroborando com os apontamentos de López, Cazorla e Panta (2019), ao afirmarem que o empreendedorismo rural pode ser enriquecido por estratégias elaboradas e avaliadas pelos beneficiários desde os estágios iniciais da formulação.

Analisando os resultados da pesquisa percebe-se que a maioria dos entrevistados apresenta alguma característica ou atitude empreendedora. Desse modo, na sequência o Quadro 7 descreve uma síntese dos resultados obtidos a partir da realidade vivenciadas pelos produtores rurais que participaram da pesquisa. 


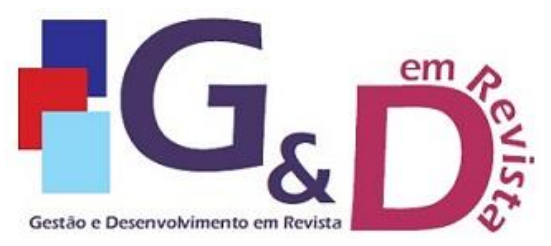

Gestão e Desenvolvimento em Revista V. 7, N. 1, jan-jun/2021, p. 37-58.

ISSN online: $2446-8738$

Artigo recebido em: 21/06/2021

Artigo aprovado em: 31/08/2021

QUADRO 7 - Síntese geral dos resultados.

\begin{tabular}{|c|l|}
\hline Objetivos & \multicolumn{1}{|c|}{ Síntese dos resultados } \\
\hline \multirow{5}{*}{$\begin{array}{c}\text { Características dos } \\
\text { empreendedores rurais }\end{array}$} & $\begin{array}{l}\text { Os produtores rurais da região estudada apresentam perfil } \\
\text { empreendedor porque, são indivíduos que tem habilidades } \\
\text { administrativas, fazem a gestão do empreendimento de } \\
\text { forma competente, com grande envolvimento da família. } \\
\text { Além disso, buscam estar atentos quanto ao que acontece } \\
\text { no mercado, por exemplo, as mudanças tecnológicas, as } \\
\text { altas e baixas dos preços dos produtos, a qualidade exigida } \\
\text { pelo mercado consumidor. São também conhecedores do } \\
\text { produto produzido dentro das propriedades, de quais } \\
\text { técnicas produtivas para cada cultura, e no caso de } \\
\text { mudanças buscam pelo conhecimento, e acompanhamento } \\
\text { da produtividade e das novas formas de produção. }\end{array}$ \\
\hline $\begin{array}{l}\text { São atitudes necessárias, tomadas pelo empreendedor, pois } \\
\text { de nada adianta características empreendedoras se nada for } \\
\text { feito de concreto. Foram diversas atitudes percebidas nas } \\
\text { entrevistas realizadas, como a diversificação produtiva, com } \\
\text { atitudes empreendedoras dos } \\
\text { empreendedores rurais }\end{array}$ & $\begin{array}{l}\text { a realização de diferentes culturas, a busca por } \\
\text { conhecimento, a disposição em aderir novas tecnologias, } \\
\text { compartilhamento de riscos junto a cooperativas da região e } \\
\text { a persistência, essa última talvez a mais importante, porque } \\
\text { o produtor rural trabalha diretamente ligado a fatores } \\
\text { naturais, clima, tipo de solo, época de cada cultura, entre } \\
\text { outros que influenciam diretamente no desempenho das } \\
\text { atividades agropecuárias. }\end{array}$ \\
\hline
\end{tabular}

Fonte: Os autores (2019).

\section{CONSIDERAÇÕES FINAIS}

O desenvolvimento do empreendedorismo é importante para qualquer nação, pois se trata de um processo que provoca mudanças nos ambientes organizacionais e nos métodos produtivos de trabalho. Potencializa o surgimento de novos negócios, que tem como consequência, novos postos de trabalho e maior renda distribuída, o que por sua vez é favorável economicamente, devido ao maior volume de capital circulando em todos os setores da economia.

Nesse contexto, o Brasil é destaque nas atividades empreendedoras, e se tratando de um país ligado as atividades agropecuárias é importante que os produtores rurais sejam percebidos como empreendedores. Portanto, o empreendedorismo pode ser realizado de forma tradicional, nas áreas urbanas, ou por meio das atividades agropecuárias, como empreendedorismo rural.

O presente estudo teve como objetivo analisar as características empreendedoras dos empreendedores rurais em um município paranaense. Dessa forma, foi possível inferir que os produtores rurais da região estudada apresentam diferentes características e atitudes empreendedoras. Constatou-se que os empreendedores rurais do estudo apresentam características e atitudes empreendedoras que os movem a realizarem suas atividades cotidianas. Atitudes e características consideradas como parte do processo empreendedor. Notou-se que os produtores rurais desenvolvem o processo empreendedor em suas propriedades. Atuam cotidianamente interagindo com fatores que influenciam no desenvolvimento das atividades da propriedade rural, principalmente, fatores naturais incontroláveis, como clima, tempo e solo.

Dessa forma, os empreendedores rurais das localidades da pesquisa apresentaram um número considerável de características e atitudes empreendedoras, que os impulsionam a agir de acordo com o exigido pelo seu 
empreendimento, dentre as características empreendedoras destacam-se o planejamento das atividades, comercialização em conjunto, bem como, o processo de compartilhamento de riscos entre os agricultores mais próximos territorialmente.

O contexto familiar representa ser fator que tem relevante influência nos empreendimentos rurais analisados. A mão de obra familiar pode ser caracterizada como a base de sustentação, principalmente, das pequenas propriedades. Empreendedores, em propriedades menores, com o apoio dos demais familiares, são os responsáveis pela execução das atividades cotidianas.

Dentre as atitudes empreendedoras adotas pelos empreendedores rurais destacam-se três: i) a diversificação produtiva; ii) a habilidade que os produtores tem em aderir novas tecnologias; e iii) a persistência. A atitude de diversificação da produção visa manter ou aumentar a lucratividade da propriedade. A ideia central é que as culturas menos lucrativas sejam compensadas pelas mais lucrativas, mantendo desempenho satisfatório do empreendimento. A habilidade em aderir a novas tecnologias busca o acompanhamento da evolução do mercado nas diferentes e novas formas de produção, e assim, produzir com qualidade conforme as exigências do mercado consumidor. A persistência pode ser considerada a atitude mais importante do empreendedor rural, porque seu trabalho está diretamente ligado com fatores sociais, econômicos, políticos e ambientais.

Finalmente, cabe destacar que o empreendedorismo rural tem como atores os produtores rurais, que mediante utilização dos recursos disponíveis desenvolvem seus empreendimentos e inovam processos produtivos. Produtores rurais com viés empreendedor têm maior probabilidade de sucesso porque possuem competências no desenvolvimento de suas atividades; habilidades que proporcionam melhor desempenho dos empreendimentos rurais. Uma caracterização que junto a conhecimentos técnicos e gerenciais, além de experiência de mercado, formam a base sólida para condução da propriedade.

O empreendedor tradicional retrata um indivíduo visionário que percebe e aproveita as oportunidades do mercado. Atua com dedicação, determinação, dinamismo e paixão pelo que está fazendo. Com sabedoria na tomada de decisões e de forma organizada no processo de gestão e liderança, apresenta como resultados a criação de valor para a sociedade. O empreendedor rural apresenta as mesmas características. É capaz de perceber e as oportunidades e se antecipar às ameaças mercadológicas, garantindo a venda de seus produtos. Compartilha riscos por meio de vínculos junto a associações e cooperativas de determinada região, tem habilidades para a diversificação da produção se necessário, é persistente e recomeça diante das intempéries impostas pelos fatores ambientais. Talvez essas últimas as características mais importantes ao empreendedor rural, já que têm como ambiente de trabalho a natureza, dependendo de fatores climáticos que são incontroláveis ao indivíduo.

Portanto, tanto empreendedores tradicionais, quanto empreendedores rurais são determinantes para a economia de um país, ainda que vivenciem contextos distintos e tenham que interagir com fatores diferenciados em seus empreendimentos.

Para futuras pesquisas, a sugestão é que sejam realizados novos estudos nas demais regiões do município, abrangendo um número maior de localidades. Uma investigação mais ampla permitiria encontrar convergências e divergências entre características e atitudes empreendedoras capazes de constituir um perfil. Novas pesquisas também podem ser realizadas em outros municípios. Isso 
permitiria entender quem são os empreendedores rurais, as diferenças e as semelhanças que ocorrem de um município a outro nas questões empreendedoras. Como os produtores rurais se caracterizam e agem no desenvolvimento de suas atividades, bem como, os produtos produzidos, e se existem algumas características ou atitudes diferentes, não percebidas nos empreendedores analisados. Investigação que possibilitaria a definição de temáticas e categorias a serem testadas em futuras pesquisas quantitativas.

\section{REFERÊNCIAS}

ARNOLD, G. Empreendedorismo rural: um estudo sobre a inserção do técnico em agropecuária, egresso do IFRS - Campus Sertão. 2011. Disponível em: <http://www.scielo.org>. Acesso em: 20 Set 2018.

BALDIN, N.; MUNHOZ, E. M. B. Educação ambiental comunitária: uma experiência com a técnica de pesquisa snowball (bola de neve). Ci. Inf. v 27 Jul-Dez 2011. Disponível em: <https://periodicos.furg.br>. Acesso em: 23 Mar 2019.

BERNARDO, E. G.; RAMOS, H. R.; VILLS, L. Panorama da produção científica em empreendedorismo rural: um estudo bibliométrico. 2019. Disponível em: <www.regepe.org.br>. Acesso em: 08 Nov 2019.

BRACHT, D. E.; WERLANG, N. B. Competências empreendedoras: uma investigação com produtores rurais catarinenses. Ci. Inf. v. 4 n. 1 2015. Disponível em: <http://www.regepe.org.br/regepe>. Acesso em: 01 Ago 2018.

BRESSANT, J.; TIDD, J. Inovação e empreendedorismo. Porto Alegre: Bookman, 2009.

CAMPOS, T. M.; LIMA, E. DE. O. Um estudo sobre os fatores que influenciam no desenvolvimento de competências empreendedoras. 2010. Disponível em: <http://www.spell.org.br>. Acesso em: 01 Abr 2019.

CASARIN, H. DE. C. S.; CASARIN, S. J. Pesquisa científica: da teoria à prática. Curitiba: InterSaberes, 2012.

CELLA, D. Caracterização dos fatores relacionados ao sucesso do empreendedor rural. 2002. Disponível em: <www.teses.usp.br>. Acesso em: 11 Set 2018.

CRUZ, Rosane. Valores dos empreendedores e inovação em pequenas empresas de base tecnológica. Tese (Doutorado em Administração), FA-URGS, Porto Alegre, 2005. Disponível em <http://www.lume.ufrgs.br/handle/10183/6512> Acesso em :29/08/2018.

DAS, S.; PATNAIK, S. K.; PATRA, A. Problems and Prospects of Rural Entrepreneurship in Mayurbhanj District of Odisha. Small Enterprises Development, Management \& Extension Journal, v. 46, n. 3, p. 152-160, September 2019. Disponível em: <https://journals.sagepub.com/doi/abs/10.1177/0970846419863873?journalCode=sd ea>. Acesso em: 21 de fevereiro de 2020. 
DORNELAS, J. C. A. Empreendedorismo: transformando ideias em novos negócios. Rio de Janeiro: Elsevier, 2005.

DORNELLAS, M. F.; MAIA, M. C. Q. Empreender por oportunidade $\mathbf{x}$ empreender por necessidade. 2018. Disponível em: <http://institutogate.com.br>. Acesso em: 22 Jun 2019.

ECKHARDT, J. T.; SHANE, S. A. Opportunities and entrepreurship. Journal of Management, 29, 333-349, 2003. Disponível em: $<$ https://www.researchgate.net/publication/228542263 Opportunities and Entrepren eurship Journal of Management>. Acesso em: 29 Ago 2018.

FEGER, J. E.; VIEIRA, R. D. S.; CHEMIN, M. Relação entre as características centrais empreendedoras e o processo de criação de empresas: um estudo exploratório. Ci. Inf. v. 15, n. 3, p. 1035-1064, 2016. Disponível em: <http://www.spell.org.br>. Acesso em: 08 Set 2018.

FELIPE, E. S.; SANTOS, A. S. Empreendedorismo: discussão conceitual, definições e um panorama do caso brasileiro. 2017. Disponível em: $<$ http://www.spell.org.br>. Acesso em: 24 Mar 2019.

FERREIRA, J. B.; LASSO, S. V.; MAINARDES, E. Características empreendedoras do produtor rural capixaba. Ci. Inf. v. 33 n. 99, p. 74-90, Set-Dez 2017. Disponível em: <http://www.spell.org.br>. Acesso em: 19 Set 2018.

GARTNER, W. B. Who is na entrepreneur? Is the question. American journal of small business. v. 12 n. 4, p. 11-32, 1988 . Disponível em: <https://springzabdesk.szabist-isb.edu.pk/>. Acesso em: 26 Jul 2018.

GIL, A. C. Métodos e técnicas de pesquisa social. São Paulo: Atlas, 2014.

HAIR JR, J. F.; BABIN, B.; MONEY, A. H.; SAMOUEL, P. Fundamentos de métodos de pesquisa em administração. Porto Alegre: Bookman, 2005.

HISRICH, R. D.; PETERS, M. P.; SHEPHERD, D. A. Empreendedorismo. Porto Alegre: Bookman, 2009.

KRÜGER, C.; MINELLO, I. F. Atitude empreendedora em discentes de graduação: entre a teoria e prática. Ci. Inf. v 24, n 2 Abr-Jun 2017. Disponível em: $<$ http://www.spell.org.br>. Acesso em: 26 Set 2018.

LIMA, C. C. DE. O empreendedorismo rural e a agroindústria familiar na gestão da atividade agropecuária em Rondônia. Revista de Administração e Contabilidade RAC. 2015.

LIMA, D. A. A. Análise das barreiras que impactam a transformação do agricultor familiar em empreendedor rural. 2010. Disponível em: $<$ https://www.puc-rio.br>. Acesso em: 11 Set 2018.

LIU, C.; YE, L.; FENG, B. Migrant entrepreneurship in China: entrepreneurial transition and firm performance. Small Business Economics, v. 52, n. 3, p. 681696, 2019. Disponível em: <https://link-springer- 
com.ez132.periodicos.capes.gov.br/article/10.1007/s11187-017-9979-y>. Aceso em: 21 de fevereiro de 2020.

LÓPEZ, M.; CAZORLA, A.; PANTA, M. D. P. Rural Entrepreneurship Strategies: Empirical Experience in the Northern Sub-Plateau of Spain. Sustainability, v. 11, n. 5 , p. 1243, $01 \quad$ February 2019. Disponível em: <https://doaj.org/article/23dd7647f3304f7c9473abb67e3f631a>. Acesso em: 21 de fevereiro de 2020.

MARCONI, M. DE. A.; LAKATOS, E. M. Metodologia científica: ciência e conhecimento científico, métodos científicos, teoria, hipóteses e variáveis, e metodologia jurídica. São Paulo: Atlas, 2011.

MORAES, E. D. M. DE. A importância de programas governamentais para incentivar o empreendedorismo no meio rural. 2011. Disponível em: $<$ https://www.webartigos.com>. Acesso em: 29 Set 2018.

MUÑOZ, P.; KIMMITT, J. Rural entrepreneurship in place: an integrated framework. Entrepreneurship \& Regional Development, v. 31, n. 9-10, p. 842-873, 20 October 2019. Disponível em: <https://wwwtandfonline.ez132.periodicos.capes.gov.br/doi/full/10.1080/08985626.2019.1609593> . Acesso em: 21 de fevereiro de 2020.

PETERS, P. P.; HISRICH, R. D. Empreendedorismo. 5o edição. São Paulo: Bookman, 2002.

PORCARO, E. de O. O empreendedor e seu perfil psicológico: um estudo comparativo entre Brasil e Portugal, 2006. Dissertação (Mestrado em Administração Geral) - Faculdade de Economia e Finanças IBMEC, Rio de Janeiro, 2006. Disponível em: <http://www.spell.org.br>. Acesso em: 28 Ago 2018.

RICHARDSON, R. J.; PERES, J. A. DE. S.; WANDERLEY, J. C. V.; CORREIA, L. M.; PERES, M. DE. H. DE. M. Pesquisa social: métodos e técnicas. São Paulo: Atlas, 2010.

ROCHA JUNIOR, C. J. G. DA.; CABRAL, R. M. O processo de transição de empreendimentos rurais tradicionais para as agroindústrias associativas no estado de Pernambuco: desafios para construir competências empreendedoras. Ci. Inf. v. 32, n. 94, p. 68-83, Jan-Abr 2016. Disponível em: <http://www.spell.org.br>. Acesso em: 04 Nov 2018.

SEBRAE. Pequenos negócios em números. 2018. Disponível em: $<$ http://www.sebrae.com.br>. Acesso em: 28 Ago 2018.

SEBRAE. Programa Empretec. 2014. Disponível em: <www.sebrae.com.br>. Acesso em: 23 Set 2018.

SENAR. Programa empreendedor rural. 2014. Disponível em: <http://senarms.org.br>. Acesso em: 30 Out 2018.

SERTEK, P. Empreendedorismo. Curitiba: InterSaberes, 2012. 
SHAKIR, M. Personal Characteristics as Determinants of Entrepreneurial SelfEfficacy among University Students in Pakistan. Journal of Education and Educational Development, v. 6, n. 2, p. 343-356, Dec. 2019. Disponível em: $<$ https://files.eric.ed.gov/fulltext/EJ1235025.pdf>. Acesso em 17 de fevereiro de 2020.

SOHNS, F.; DIEZ, J. R. Explaining micro entrepreneurship in rural Vietnam-a multilevel analysis. Small Business Economics, v. 50, n. 1, p. 219-237, 2018. Disponível em: <https://dx.doi-org.ez132.periodicos.capes.gov.br/10.1007/s11187017-9886-2>. Acesso em 17 de fevereiro de 2020.

TOMEI, P. A.; LIMA, D. A. O empreendedor rural e a inovação no contexto brasileiro. 2015. Disponível em: <http://www.inovarse.org>. Acesso em: 17 Set 2018.

VERGARA, S. C. Métodos de pesquisa em administração. São Paulo: Atlas, 2011.

WEBER, J.; MORGAN, A.; WINCK, C. A. Empreendedorismo rural sustentável no contexto oeste catarinense: um estudo de caso no município de Guatambu. Passo Fundo: Encontro de Estudos sobre Empreendedorismo e Gestão de Pequenas Empresas, 2016. 